\title{
Metka SITAR
}

\section{Strategije razvoja mest med evropeizacijo, državo in regijo}

Prostorski in regionalni razvoj v strateških dokumentih Evrope in njenih nacionalnih držav, med njimi tudi Slovenije, v skladu z načeli trajnostnega razvoja poudarja zlasti cilje in usmeritve uravnoteženega prostorskega razvoja, medtem ko sodobni urbanizacijski procesi, odvisni od globalne konkurenčnosti postindustrijske dobe, poudarjajo vodilno vlogo velikih urbanih središč. Po drugi strani strukturna preobrazba Evrope vedno bolj spreminja prostorska razmerja med državami, regijami, mesti in aglomeracijami. Govorimo o nujnosti drugačnega perspektivnega pogleda na razvoj mest in urbanih območij, ki v središče prostorskih politik in strategij postavlja integralno obravnavo prostora. Pogoje za uspešno, konkurenčno urbano ekonomijo lahko oblikuje le $v$ povezavi z ekonomsko politiko ter drugimi prostorsko relevantnimi sektorskimi politikami (prometno, okoljsko, kmetijsko itd.), z željo po splošni blaginji pa se ji vedno bolj izrazito pridružuje še komponenta socialne kohezije. Prispevek v posameznih poglavjih predstavlja raznovrstne globalne, regionalne in lokalne dejavnike in v evropskih razmerah prepoznava najznačilnejše dejavnike vloge in funkcij $v$ razvoju mest. Na osnovi različnih teoretičnih izhodišč in izbranih praktičnih primerov iz različnih urbanih okolij poskuša opredeliti možnosti za prepoznavanje spodbud in priporočil za oblikovanje razvojnih politik in strategij, bistvenih tudi za slovenske razmere.

\section{Opredelitev razvoja mest $\mathrm{v}$ globalni perspektivi}

Prostorske strukture so manifestacije ekonomskega, socialnega in političnega razvoja (Bornsdorf, 2004). Že desetletja vodilne usmeritve nacionalnih in regionalnih politik ter
In European and national strategic documents, even Slovene ones, emphasis in physical and regional development, which is aligned to principles of sustainable development, is on goals and directions for balanced spatial development, while contemporary urbanisation processes, conditioned by global competitiveness of the post-industrial age, underline the leading role of large urban centres. On the other hand structural transformations in Europe are increasingly changing spatial relations between states, regions, cities and agglomerations. With growth of economic and infrastructure flows and strategic enforcement of transnational authority a uniform European economic and social space is emerging, in which different integrations are substituting the role of states. We are deliberating on the necessity of changing the viewpoint on prospective development of cities and urban regions, whereby focus of spatial policies and strategies is on integral dealings with space. Conditions for successful, competitive urban economy can be established only by connecting economic policies with other spatially-relevant departmental policies (transport, environment, agriculture etc.); with general welfare as the goal, another component is becoming significantly closer, which is social cohesion. In different chapters the article presents various global, regional and local factors and in European circumstances identifies the most typical factors affecting roles and functions in city development. Starting from various theoretical embarkation points and selected practical examples from different urban environments, the article tries to define possibilities for identifying initiatives and recommendations for designing development policies and strategies that are essential even in Slovene circumstances.

strateških dokumentov v Evropi poudarjajo cilje prostorsko uravnoteženega razvoja. Enako velja za skupna načela in smernice prostorske politike Evropske unije[1], ki predstavlja izhodišča za usmerjanje prostorskega razvoja na osnovi kohezijske politike. Po drugi strani globalizacijski procesi spodbujajo razvoj urbanega sistema, ki upošteva ekonomski pomen
Evropa

Evropska unija

Razvoj mest

Urbana mreža

Urbani sistem

Europe

European Union

Urban

development

Urban network

Urban system 
koncentracije in ki v skladu s tem poudarja vodilno vlogo velikih urbanih središč. Takšen razvoj, podprt z globalno konkurenčnostjo v prostoru, sprožajo ekonomski procesi postindustrijske dobe, v katerih se povečuje vloga storitvenega sektorja $\mathrm{v}$ povezavi $\mathrm{z}$ razvojem modernih informacijskih in komunikacijskih tehnologij. V ospredje razvojne uspešnosti postavlja atribute, kot so ekonomska rast, podjetniško okolje, inovativnost itd., ki pogojujejo koncentracijo gospodarskih dejavnosti (DISP, 2005).

Čeprav se evropski urbani sistem omrežja velikih in manjših mest $\mathrm{v}$ zadnjih desetletjih $\mathrm{v}$ osnovi ni bistveno spremenil, so globalizacijski tokovi vplivali na vlogo in funkcijo posameznih mest ter jo povečali ali oslabili v njihovem nacionalnem in regionalnem kontekstu glede na sposobnost prilagajanja gospodarskim razmeram. Po drugi strani strukturna preobrazba Evrope spreminja prostorska razmerja med državami, regijami, mesti in aglomeracijami ${ }^{[2]}$, ne ozirajo se ne na politične ne teritorialne meje. Tradicionalne funkcije mesta kot edinstvene lokacije raznovrstne gospodarske dinamike, kulturne in socialne ponudbe se postopoma izgubljajo in zlivajo $\mathrm{v}$ različnih (regionalnih) urbanih omrežjih, ki so komplementarna razvoju globalnih mest in aglomeracij. Ob naraščanju ekonomskih in infrastrukturnih tokov ter strateškem uveljavljanju transnacionalnih oblasti se postopoma oblikuje enoten evropski gospodarski in socialni prostor, v katerem različne integracije vse bolj nadomeščajo vlogo države.

S postopnim uresničevanjem vizije Evrope se tako korenito spreminja tudi pojmovanje usmerjanja prostorskega razvoja in urejanja prostora, v preteklosti determiniranega znotraj nacionalnih, regionalnih in drugih meja. Govorimo o nujnosti drugačnega perspektivnega pogleda, ki v ospredje prostorskih politik postavlja integralno obravnavo prostorskega razvoja. V povezavi z ekonomsko politiko ter drugimi prostorsko relevantnimi sektorskimi politikami (prometno, okoljsko, kmetijsko itd.) ustvarja razmere za uspešno, konkurenčno urbano ekonomijo. V nacionalni in regionalni politiki je tako vedno bolj opazna potreba po novih instrumentih vertikalnega in horizontalnega povezovanja, ki vključujejo javne in zasebne akterje. Temu se pridružujejo tudi sodobna stališča urbanih sociologov, ki sicer mesta in moderna zgoščena urbana območja prepoznavajo kot prostor za integrirani razvoj tudi v prihodnosti, ven- dar atributom za gospodarsko rast pridružujejo komponento socialne enakosti in kohezije za doseganje splošne blaginje.

\section{Razvojni procesi in hierarhije urbane Evrope}

Urbanizacija je proces, ki je postal eno temeljnih vprašanj 21. stoletja in v katerem so globalni akterji prav mesta in urbane regije. (MVRDV, 2002) Rezultat je zdajšnji urbani sistem, ki odraža zgodovinski razvoj in postopoma spreminja ozemlje Evrope v njegovi ekonomski, politični, sociološkokulturni, pa tudi v fizični in strukturni podobi. Spremembe prehoda od industrijske proizvodnje $\mathrm{k}$ storitveno naravnanemu gospodarstvu, pospešena gradnja prometnih povezav, komunikacij in infrastrukture, odnosa med javnim in zasebnim sektorjem so najzrazitejši procesi, ki vplivajo na razvoj prostorskih struktur. Prilagajanje spremenjenim razvojnim okoliščinam oblikuje tudi nov red pristojnosti t. i. globalizacije, v katerem transnacionalne strukture vedno bolj nadomeščajo vlogo države.

Procesi postindustrijske dobe postavljajo nova merila razvojne uspešnosti in učinkovitosti razvoja mest in aglomeracij. Cilji in strategije ekonomskega, podjetniško usmerjenega urbanega razvoja poudarjajo zlasti sposobnost konkurenčnosti za pritegnitev najpomembnejših gospodarskih subjektov. Mednarodna tekma konkurenčnosti alokacij različnih funkcij in dejavnosti poteka v Evropi odvija med nekaj velikimi mestnimi aglomeracijami, ki doživljajo pravi razcvet kot nova središča moči na regionalnem, nacionalnem ali mednarodnem gospodarskem ali političnem prizorišču, medtem ko druga mesta, ki se jim ni uspelo prilagoditi novim postindustrijskim razmeram, doživljajo gospodarsko nazadovanje in $\mathrm{z}$ njim povezane negativne strukturne spremembe. Značilnost uspešnih mest je tako vedno večja koncentracija delovnih mest, razvoj prometnih povezav pa omogoča dobro prometno dostopnost do stanovanjskih in drugih funkcij kakovostnega življenja. (MVRDV, 2002)

Osnovno vprašanje za oblikovanje prihodnjih politik in strategij $\mathrm{v}$ novih globalizacijskih razmerah se tako ukvarja predvsem $z$ vpraša- 
njem aktualne vloge in funkcij mest in urbanih sistemov kot odločilnih dejavnikov ekonomske uspešnosti nacionalnih držav. Katere so značilnosti uspešnega mesta, aglomeracije, regije $\mathrm{v}$ merilih konkurenčnosti evropskega prostora? Odgovore najdemo v različnih hierarhičnih opredelitvah in sistemih kategorizacije, ki poskušajo pojasniti vzroke in posledice različne vloge mest. Razvijajo različne tipologije na osnovi dveh ključnih dimenzij, ki odločilno vplivata na urbano hierarhijo: (i) sposobnost prilagajanja spremembam prehoda iz industrijske proizvodnje $\mathrm{k}$ fleksibilnemu specializiranemu gospodarskemu sistemu ter (ii) sposobnost mesta, da razvija različno »kontrolno kapaciteto « na gospodarskem, političnem, socialno-kulturnem področju v širšem, nadnacionalnem, evropskem ali celo svetovnem merilu. Te funkcije se nanašajo na pomembna finančna središča, centralne sedeže gospodarskih družb, mednarodnih organizacij, pa tudi različnih festivalov, športnih prireditev itd. (Brenner, 2000: v Ache, 2004) [3]

\subsection{Policentrizem in kohezija}

Ob novih tipologijah proizvodnje in tehnologije ter naraščajočih zahtevah potrošnikov se spreminjajo tudi veljavni prostorski in $\mathrm{z}$ njimi življenjski vzorci. Zdi se, da razvoj mest in urbanih regij bolj kot planerji definirajo ekonomsko podprti imperativi investitorjev, katerih interesi se zaradi različnih vzrokov vedno bolj raztezajo daleč v zaledja velikih mest in mestnih aglomeracij. Sodobne ekonomske razmere zahtevajo nove oblike prostorske organizacije dejavnosti in funkcij, ki spreminjajo stare in ustvarjajo nove urbane strukture, kot so npr. policentrični urbani sistemi, funkcionalne urbane regije itd., ki naj bi posameznim mestom vrnile zagon. Nove strukture poskušajo na osnovi medsebojnega mrežnega povezovanja zagotoviti posameznim mestom in aglomeracijam vključevanje v ekonomsko uspešno, dinamično, privlačno širše urbano okolje. V teh procesih se spreminja zlasti vloga državnih oblasti, ki se počasi in vztrajno zmanjšuje, obenem pa se povečuje vloga regionalnih in lokalnih oblasti, oprta na aktivno sodelovanje z zasebnim sektorjem.

Tudi evropski prostorski dokumenti v okviru teženj za uravnotežen prostorski razvoj opredeljujejo dve ravni urbanih sistemov mest (ESDP, 1999):

- raven celotne EU z velikimi mesti kot dinamičnimi središči rasti s težnjo po kon- centraciji gospodarskih aktivnosti v osrednjih regijah, s čimer so druga območja avtomatično postala obrobna;

- raven evropskih regij, v katerih dominantno središče zamenjuje vrsta med seboj povezanih mest; tipična primera takšne regije sta urbani omrežji regije Randstad na Nizozemskem in Porenje v Nemčiji; obrobnim regijam pripadajo pretežno podeželska območja z majhnimi in srednje velikimi mesti.

Takšna vodilna podoba razvoja (uravnoteženega) policentričnega sistema mest je v skladu s cilji socialne in teritorialne kohezije, zapisane v pogodbi Unije. Komponenta teritorialne kohezije je vgrajena $\mathrm{v}$ evropske prostorske strategije s ciljem, da poudari integracijo med različnimi sektorskimi politikami na določenem ozemlju, pri čemer poudarja njeno prostorsko dimenzijo. Takšna načela upošteva oblikovanje osrednjih regij po vsej Evropi, med katerimi je v nadaljevanju kot eden najuspešnejših primerov integracije sektorskih politik nacionalne politike predstavljeno administrativno regionalno omrežje Randstad.

\subsection{Primer policentrične urbane regije: RANDSTAD, Nizozemska [4]}

Funkcionalno izrazito raznovrstno območje s 7,5 milijona prebivalcev sestavljajo mesta in province na zahodu Nizozemske, nanizana po robu naravnih rezervatov (»zeleno srce $\ll$ ). Urbana regija je »motor $«$ gospodarskega razvoja, katerega osnova so na znanju temelječi industrije, inovacije, poslovne in finančne storitve in turizem. Štiri nizozemska mesta, Amsterdam - mednarodno storitveno središče, Rotterdam - svetovno logistično središče, Den Haag - upravno središče nizozemske vlade in mednarodnih organizacij, Utrecht - nacionalno storitveno središče, imajo komplementaren ekonomski profil. Če na kratko povzamemo strateške usmeritve policentrične regije Randstad, ugotovimo, da je ključni dejavnik mednarodne konkurenčnosti vsestranska dostopnost (letalski, ladijski, cestni, železniški prevoz), ki se oblikuje na osnovah povezav TEN-transevropskega omrežja. Mednarodno investicijsko okolje poleg visokokakovostnih poslovnih lokacij zahteva tudi visoko kakovost stanovanjskih območij s poudarkom na okoljskih kvalitetah, vključno z razvojem ruralnih območij in upravljanjem obalnih con. Oba pogoja za 
uspešnost celotne regije se uresničujeta $\mathrm{z}$ intenzivno notranjo kohezijo, ki temelji na dostopnosti na osnovi modalnosti v različnih transportnih verigah na celotnem ozemlju.

\subsection{Poskus sistematizacije urbanih sistemov}

S prikazanimi teoretičnimi izhodišči in zgledi iz prakse ugotavljamo, da so različni dejavniki za uspešnost mest in aglomeracij vezani na izboljšanje njihove konkurenčnosti na regionalni, nacionalni in mednarodni ravni. Obenem vprašanje njihove velikosti in funkcije vedno bolj poudarja nujnost medsebojnega mrežnega povezovanja $v$ različne urbane sisteme. V poskusu sistematizacije povzemamo glavne smeri razvoja in njihove značilnosti, ki jih lahko opredelimo tudi kot izhodišča za usmeritve nacionalnih/regionalnih urbanih sistemov [5] (CEERD-RePUS, 2004):

- Koncentracija: vpliva na rast »globalnih mest « in je mednarodni policentrični sistem metropol tradicionalno konkurenčnih mest na osnovi dominantnih funkcij (institucionalnih, tehnoloških, inovacijskih, finančnih itd.) in visokokakovostnih storitev z močnim vplivom na konkurenčnost celotne države (London, Pariz, Bruselj, Frankfurt itd.);

- Decentralizacija: skupaj z aktivno politiko za dvig privlačnosti mest pospešuje vlogo drugih velikih mest kot potencialnih polov za uravnotežen razvoj globalnih mest; njihova vloga je sicer pretežno nacionalno/regionalna, vendar evropsko pomembna, saj kot sekundarni urbani sistem sovplivajo na sposobnost držav (Barcelona, Toulouse, Lyon, Milano itd.);

- Oblikovanje urbanih regij: srednje velika mesta, ki kot regionalna središča igrajo aktivno vlogo $v$ naraščajočem decentraliziranem nacionalnem sistemu; v povezavah z drugimi regionalnimi območji in središči oblikujejo subregionalni urbani sistem, kar je značilnost večine decentraliziranih držav (Nemčija, Italija itd.).

\section{Razvoj mest v nacionalni/regionalni perspektivi}

Neuravnotežen razvoj urbanih sistemov v različnih nacionalnih in regionalnih okoljih določa nadaljnjo delitev ekonomskih aktivnosti med posamezna mesta, aglomeracije in urbane regije. Za opredelitev značilnosti in funkcij uspešnih mest po Kunzmannu (2004) povzemamo prostorske opredelitve urbanega razvoja, ki ga $\mathrm{z}$ vidika urbane ekonomije $v$ nacionalnem/regionalnem merilu obvladujeta dva izrazito prostorsko determinirana trenda. Prvi je prostorska polarizacija, ki daje prednost središčnemu položaju velikih mest in aglomeracij pred obrobnimi, saj jim pripisuje večje konkurenčne sposobnosti internacionalizacije, dobro transportno infrastrukturo, sodobne produkcijske in komunikacijske sisteme itd., ki zagotavljajo najboljše razmere za različne dejavnosti. Nasprotno pa funkcijska polarizacija dejavnosti vključuje tudi srednje velika in manjša mesta kot središča specializirane proizvodnje (avtomobilska industrija, optični izdelki itd.). Svojo podobo - image lahko takšna mesta razvijajo z naraščajočo specializacijo, ki s promoviranjem ekonomskega razvoja privablja raznlične javne in zasebne naložbe. Pri tem je bistvenega pomena za konkurenčnost medsebojno mrežno povezovanje posameznih funkcij, ki zagotavlja potrebno kooperacijo in koordinacijo za ekonomsko in socialno uspešnost mest tako $\mathrm{v}$ regiji kot tudi $\mathrm{v}$ širšem nacionalnem in mednarodnem okolju.

\subsection{Sistemi mrežnega povezovanja}

Eden od uspešnih konceptov mrežnega povezovanja specifičnih dejavnosti v tehnološka omrežja (clustering) temelji na pričakovanju nadaljevanja zmanjševanja in specializacije podjetij. Takšno organizacijsko povezovanje sorodnih dejavnosti je bistvenega pomena zlasti za razvoj manjših mest, ki kot težišča specializiranih dejavnosti obenem spodbujajo razvoj prometne in telekomunikacijske infrastrukture - zlasti če v regiji prevladuje ena industrijska veja ali gospodarska družba (verjetno najbolj znan primer prestrukturiranja območja Porenja, Nemčija).

Pomemben vidik mreženja je tudi razvoj novih, na znanju temelječih industrijskih dejavnosti, ki poudarja področje raziskav in izobraževanja. Ekspertno znanje, ki ga zahtevajo nove tehnologije, lahko praviloma, skupaj z raziskovalnimi institucijami, zagotavlja le univerzitetno okolje. Razvoj takšnega, visokokakovostnega okolja za doseganje mednarodne konkurenčnosti pa je praviloma dolgoročen proces, vezan na velika fi- 
nančna sredstva, vendar ni dosegljiv. Uspešne primere poznamo tudi $v$ naši bližnji soseščini (primer: avstrijski Gradec, ki že vrsto let uspešno razvija avtomobilski clustering, po najnovejših podatkih $\mathrm{z}$ namenom širitve $\mathrm{v}$ mariborsko poslovno cono).

Številna manjša mesta so si opomogla tudi ob pomoči storitvenega sektorja, ki temelji na drugačnih lokacijskih dejavnikih kot produkcijsko usmerjene dejavnosti in se tudi drugače odziva $v$ razmerah mreženja. $\mathrm{Na}$ alokacijo sodobno zamišljenih storitvenih dejavnosti vplivajo namreč tudi izrazito neurbani dejavniki, med njimi zlasti nižji stroški, ki ustvarjajo priložnosti za konkurenčnost lokacij $\mathrm{v}$ manjših mestih in na obrobnih območjih. Zagotavljanje kakovosti in višjo raven storitev sicer omogoča praviloma le večje tržišče, zato v zunajmestnih lokacijah prevladujejo zahteve po dobrih prometnih povezavah s sosednjimi zgoščenimi urbanimi prostori. Z vlaganjem v razvoj prometne infrastrukture lahko tako tudi $\mathrm{v}$ manjših mestih dosežemo ustrezno merilo za različne storitvene investicije (nakupovalna, zabaviščna, športna in rekreacijska središča itd.). V teh območjih urbana ekonomija v primerjavi z metropolitanskimi regijami na splošno poudarja zlasti visoko življenjsko raven delovnih in bivalnih razmer, prevdsem pa visoko kakovost okolja (Andersen, 2003).

\subsection{Mehki strateški dejavniki}

Politike in strategije razvoja mest in urbanih območij prilagajajo svoje prioritete novim pogledom na trajnostni razvoj mest in urbanih območij, ki kot protiutež izrazito ekonomskim značilnostim poudarjajo pomen prostorske raznovrstnosti na osnovi endogenih potencialov posamezne lokacije, mesta, regije. Tako so za razvoj mest in aglomeracij vedno bolj pomembni tudi »mehki « lokacijski dejavniki, kot so kakovost bivalnega in delovnega okolja, stanovanjska in kulturna ponudba, stopnja urbanosti, varnost lokacije itd., ki sestavljajo celostno podobo, image določenega kraja, ki kaže njegovo neponovljivost (na področju turizma npr. specifični šarm in atmosfera). Mednarodno publiko privabljajo danes zlasti najrazličnejši muzeji in galerije sodobnih umetnosti, gledališča itd., veliko odmevnost pa dosegajo tudi celostno zasnovani projekti, kot so npr. mednarodno uveljavljene športne [6], kulturne in zabavne prireditve, zlasti tiste, ki so dostopne širši javnosti (mariborski festival Lent, Love Parade $\mathrm{v}$ Berlinu itd.).

Pomemben element prostorske konkurenčnosti mest tako vedno bolj postajata tudi ustvarjalnost in inovativnost, s katerima mesta kot prostori kulturne identitete (Koll-Schretzenmayr, Burkhalter, 2002) privabljajo tako investitorje kot kapital. Večina evropskih mest poskuša takšne prednosti izkoristiti v širše zastavljenih akcijskih programih, kot je npr. projekt Kulturno mesto Evrope (v preteklosti Ljubljana, avstrijski Gradec, Maribor pa predvidoma kandidira za leto 2012). Takšni programi praviloma niso izrazito dobičkonosni, vendar ima njihova izvedba daljnosežne učinke za promocijo in trženja mesta (mestni marketing).

Za srednje velika in manjša mesta se tako postavlja osnovno vprašanje, kako prilagoditi svojo ekonomsko osnovo globalnim smernicam vse bolj kompleksnega regionalnega razvoja.

Kako različni so razvojni dejavniki uspešnega, konkurenčnega mesta, za konec na primerih nemških mest nazorno prikaže povzetek nekaterih anketnih odgovorov na vprašanje, kaj pomeni pojem »podjetniško mesto « [7] (Ache, 2004):

- Frankfurt, Porenje: gosta institucionalna mreža povezav med gospodarstvom in politiko;

- Dortmund: strukturne spremembe s poudarkom na IT-tehnologijah;

- Wolfsburg: eno redkih mest, kjer gospodarstvo nadzira osrednja področja mestnega razvoja, vključno s promocijo (marketing) mesta, trgom delovne sile, zabavo in turizmom;

- Hamburg, Leipzig, Bremen: mesta in mestne regije $\mathrm{z}$ visoko gospodarsko dinamiko, ki temelji na znanju in raziskavah (univerze, inštituti);

- Stuttgart: lokacije svetovnih družb, aktivnih v Evropi, sposobne regionalne planske strukture, zaposlitvene perspektive, nizka nezaposlenost;

- München: proaktivno mesto, ki išče investitorje in pridobiva projekte; pomembne prireditve (vključno $\mathrm{z}$ nacionalnim urbanističnim kongresom); mesto promovira svojo razvojno strategijo $\mathrm{z}$ novimi instrumenti za svoj image profiliranega, fleksibilnega, podjetniškega mesta, zlasti na po- 
dročju upravljanja stavbnih zemljišč in mestnega razvoja.

Ugotavljamo, da zahteve za konkurenčen razvoj uspešnega mesta najbolj vključujejo ekonomsko pogojene dejavnike, ki ob dejavnikih izobraževanja, zabave, rekreacije itd. kažejo kulturno raznovrstnost in obenem tudi socialno enakost in kohezivnost. Takšna paleta različnih dejavnikov neizogibno zahteva uvajanje sodobnih metod in postopkov v vodenje (governance) in upravljanje mesta (management), ki organizacijsko in administrativno praviloma segajo $\mathrm{v}$ širše območje regije (npr. regionalna zveza aglomeracije Stuttgart, različne medmestne institucionalne zveze).

\section{Novi vidiki uspešnosti mestnega razvoja}

Eno temeljnih vprašanj razvoja urbanih struktur, ki se vedno pogosteje pojavlja, je vprašanje kompatibilnosti ekonomske rasti in socialne pravičnosti razvoja mest in aglomeracij $\mathrm{v}$ konkurenčnih razmerah globalizacije. Ali je »dvojna strategija«, ki po eni strani poudarja ekonomsko rast in konkurenčnost, po drugi strani pa hoče obdržati ključne elemente blaginje, sploh mogoča? V razvojnih strategijah nekaterih evropskih mest zasledimo številne razvojne usmeritve, ki poudarjajo dvojnost prostorskih indikatorjev, primerne odgovore pa najdemo zlasti v izkušnjah uresničevanja takšnih prizadevanj v praksi. Kot uspešen primer predstavljajo značilne elemente urbane strategije razvoja mesta Köbenhavn, ki je nastala na pobudo centralne vlade in se uspešno izvaja $\mathrm{v}$ širšem merilu mestne regije.

\subsection{Primer dualne urbane strategije: Köbenhavn [8]}

Prednostna področja urbane strategije mesta poudarjajo tradicionalno, h gospodarski rasti orientirano razvojno politiko, s poudarkom na spodbujanju investitorjev, ki jim mesto ponuja najboljše možnosti: visoko kvalificirano delovno silo, sodobno infrastrukturo, nizko obdavčitev, visokokakovostne javne servise, selektivno industrijsko politiko, ki je naklonjena investicijam v moderna strateška področja, kot so biotehnologija, komunikacije in sodobna elektronika. Takšna politika zahteva močno podporo vseh javnih oblasti na posameznih strateških področjih, saj vključuje tudi us- tanavljanje novih raziskovalnih institutov, sodobnih programov izobraževanja itd.

Obenem je razvoj neprednostnih območij zahteval celovito preoblikovanje urbane politike, saj je moral okrepiti naložbe v tradicionalno zapostavljeno izboljšanje propadajočih stanovanj na osrednjih mestnih lokacijah v kombinaciji z drugimi prizadevanji manj profitne narave. Lokalne oblasti so razvile nova merila in metode za splošen socialni dvig prebivalstva, ki ga pooseblja ravnotežje med skupinami prebivalstva $\mathrm{z}$ nizkimi in tistimi $\mathrm{z}$ visokimi dohodki, med neto plačniki in neto prejemniki itd. Da bi se izognili naraščajočemu številu neto prejemnikov, je eden prvih ukrepov te politike ustavitev javne stanovanjske gradnje in sistematična promocija lastništva oz. deljenega lastništva stanovanj, drugi pa prenova tradicionalno imigrantskega območja, kjer majhna, poceni opremljena stanovanja preurejajo v večja, popolnoma modernizirana in privlačna stanovanja $z$ visokimi najemninami. Centralna vlada je s takšno politiko prisilila mesto $\mathrm{k}$ dejavnejši strategiji, v katero so intenzivno vključeni tudi mestni planerji. Primer takšnega sodelovanja je prenova pristaniškega območja, ki jo vodi nacionalna planerska agencija in s katero si mesto prizadeva, da bi s preurejanjem razpoložljivih površin v draga stanovanja zvabila srednji in višji srednji sloj prebivalcev v središče mesta in s tem obenem izboljšalo svoje finančno stanje.

Drugi primer dualne strategije pa je gradnja mostu Köbenhavn-Malmö, prav tako na pobudo centralne vlade, da urbana ekonomija mesta doseže z oblikovanjem čezmejne regije Oeresund želeno merilo mednarodne metropolitanske konkurenčnosti in obenem spodbudi celostni regionalni razvoj.

\section{Perspektive vodenja razvoja mest}

Pozitivnim zgledom urbanih strategij evropskih mest, ki se odmikajo od liberaliziranih pogledov na urbane posege preteklega desetletja, se pridružujejo tudi aktualne sociološke študije in mednarodno zasnovani projekti [9], ki v mestih in urbanih aglomeracijah vidijo vodilne razvojne prostore prihodnosti. Zato posvečajo veliko pozornost kompleksnim vidikom uspešnosti mesta, ki so v prvi vrsti odvisni od sposobnosti vodenja in upravljanja 
mestnega razvoja (urban governance). V začetku 21. stoletja je tako dejansko zavel nov val optimizma v razvoju mest, ki pomeni premik od enostransko produkcijsko orientiranega zornega kota 19. in 20. stoletja k ideji o mestih, ki naj ponovno postanejo vzemirljivi in ustvarjalni prostori, v katerih živimo in delamo. Novi strateški pristopi poudarjajo »trojni « značaj uspešnega (trajnostnega) razvoja mest, ki vključuje zahteve po (ekonomski) konkurenčnosti, (socialni) koheziji in (odgovornem) vodenju (Gordon, Buck, 2005). Sodobni modeli vodenja in upravljanja mest so temu ustrezno zasnovani na principih mreženja akterjev in institucij v planerske skupine na različnih ravneh, ki vključujejo tako horizontalno kot vertikalno sodelovanje in koordinacijo. Takšne metode se vedno bolj uveljavljajo tudi v praksi, saj po McEldowneyju (2004) omogočajo široke možnosti za implementacijo različnih projektov kot elementov integriranih urbanih konceptov v regionalni perspektivi mest. Videti je, da pridobljene izkušnje zmanjšujejo vlogo prostorske regulative, saj se področja vodenja urbanega razvoja vedno bolj premikajo iz teritorialne osnove na marketinško - tudi ob pomoči različnih subvencioniranih programov Evropske unije

Doc. dr. Metka Sitar, univ. dipl. inž. arh., Univerza v Mariboru, Fakulteta za gradbeništvo, Katedra za stavbarstvo, prostorsko načrtovanje in varstvo okolja, Maribor

E-pošta: metka.sitar@uni-mb.si

\section{Opombe}

[1] ESDP - European Spatial Development Perspectives, 1999 - Evropske prostorske razvojne perspektive.

[2] $\vee$ prispevku uvajamo pojem aglomeracija po zgledu Švice, ki ga opredeljuje kot izraz za povezana urbana območja manjših krajev in lokalnih skupnosti z min. 20.000 prebivalci.

[3] Na vrhu lestvice so "globalna« mesta, kot so London, Pariz in Frankfurt; sledijo "evropske urbane regije « konurbacije Rhein-Main (Frankfurt), Köbenhavn, Randstad (Amsterdam/Rotterdam), Porurje (Dortmund -Essen-Duisburg); večja mesta - evrometropole - Atene, Bruselj, Dunaj, Rim, Madrid, Barcelona in Milano, pa tudi Berlin po združitvi. Na dnu hierarhije najdemo mesta, ki so na obrobju sodobne evropske ekonomije - kot npr. Neapelj in Cottbus - in čisto na dnu lestvice uspešnih mesta, kot sta Manchester in Duisburg, ki se še vedno spopadajo $s$ tranzicijo fordističnih produkcijskih procesov. Med njimi so na rep zmagovalcev uvrščena tudi manjša mesta, ki so nacionalna urbana središča, in tista, ki so uspešnejša $v$ prehodu na postfordistično proizvodnjo. (Brenner, 2000: v Ache, 2004)

[4] Povzeto po Economic strategy Randstad Holland, A joint metropolitan strategy and an agenda to sti- mulate the economy of an internationally competitive Randstad Holland, Regio Randstad, 2004.

[5] Povzeto po CEERD-RePUS, 2004.

[6] »London premagal Pariz $\vee$ tekmi za prizorišče olimpijskih iger 2012 ...«, Delo, 7. 7. 2005.

[7] Entrepreneurial City je pojem, ki izhaja iz ZDA in je namenjen prepoznavanju urbanih inovacij $v$ uspešnih mestih, ki ga Manhattan Institute priporoča kandidatom za novega župana mesta. (po Ache, 2004)

[8] Andersen, H. T., 2002. Urban Economic Futures, gradivo za konferenco COST C10, Kopenhagen, 2003

[9] Projekt Evropske komisije COST A26: The European city-regions in an age of multi-level governance - reconciling competitiveness and social cohesion?, 2003-2007. Ministrstvo za znanost in tehnologijo, Univerza v Mariboru, Fakulteta za gradbeništvo, Katedra za stavbarstvo, prostorsko načrtovanje in varstvo okolja.

\section{Viri in literatura}

Ache, P., 2004. WG2: Entrepreneurial cities between growth and welfare, COST A26, Malta, June 2004.

Andersen, H. T., 2002. Urban Economic Futures.

Bornsdorf, A., Zembri, P., 2004. Structures. European Cities - Insights on Outskirts, COST C10, Paris.

DISP 161, ETH, Zürich, 2/2005.

DISP 150, ORL/ETH Zürich, 3/2002.

Economic strategy Randstad Holland, 2004. A joint metropolitan strategy and an agenda to stimulate the economy of an internationally competitive Randstad Holland, Regio Randstad.

ESDP, European Spatial Development Perspectives, 1999. European Commission.

Fall, P., Pfeiffer, U., 2000. Urban Future 21, Federal Ministry of transport, Building and Housing of the Rebublic of Germany.

Gordon, I., Buck, N., 2004. Cities in the new conventional wisdom. COST A26

Kunzmann, K., Reflexionen über die Zukunft des Raumes, 2004. Dortmunder Beiträge zur Raumplanung 111, IRPUD.

McEldowney, M. (ur.), 2004. Governance. European Cities - Insights on Outskirts, COST C10, Paris.

Muster, S., Salet, W. (ur.), 2003. Amsterdam Human Capital, Amsterdam University Press.

MVRDV, The Regionmaker, 2002. RheinRuhrCity, NRWForum Kultur und Wirtschaft Düsseldorf.

Sitar, M. et al., 2005. Odprte meje - Open borders, v Mariboru, Fakulteta za gradbeništvo

Sitar, M. et al., 2004. Pomen in vloga mest in drugih naselij za prostorski razvoj Slovenije, poročilo I. faze, Ministrstvo za šolstvo, znanost in šport, Ministrstvo za okolje, prostor in energijo, Urad RS za prostorsko planiranje, Univerza v Mariboru, Fakulteta za gradbeništvo.

Strategija prostorskega razvoja Slovenije, 2004. Ministrstvo za okolje, prostor in energijo, Direktorat za prostor, Urad za prostorski razvoj.

Towards a thematic strategy on the urban environment, 2004. Commission of the European Communities, Brussels. 